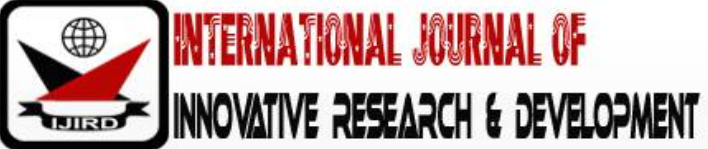

ISSN 2278-0211 (Online)

\section{Development and Validation of Entrepreneurship Education Interest Inventory (EEII) for Colleges of Education in North Eastern Nigeria}

\author{
Sulaiman Mai Umar \\ Lecturer, Department of Business Education, \\ Umar Suleiman College of Education Gashua, Yobe State, Nigeria \\ Tanko Hassan \\ Lecturer, Department of Agricultural Education, \\ Umar Suleiman College of Education Gashua, Yobe State, Nigeria
}

\begin{abstract}
:
This study developed and validated Entrepreneurship Education Interest Inventory (EEII) in Colleges of education in North-Eastern Nigeria. The study used instrumentation as its research design. The population of the study consists of all NCE II students of schools of vocational and technical education from six colleges of education, one from each state of the region which was exactly 2898 students. Samples of 952 students were randomly selected from the study area using stratified random sampling. Hidi and Renninger\&\#39;s (2006) four-phase model of interest development was used to serve as theoretical basis that inform and guided the process of development and validation of the interest inventory. The study reviewed several empirical studies conducted for development and validation of instruments. Four objectives, three research questions and one hypothesis were used for the study. The instrument revealed reasonable psychometric properties in term of construct validity, reliability and standard error of measurement. Construct validity was determined using factor analysis and Average variance extracted. The result of the factor analysis confirmed the loading of the variables to the four factors as propounded by Hidi Renninger. The EEII has evidence of convergent construct validity among five items each for the four factors (Knowledge, Engagement, Emotion and Value) with average variance extracted of $0.8008,0.7948,0.7702$, and 0.77 respectively. The instrument has high reliability index estimated to be .878 using Cronbach\&\#39;s Alpha. The instrument also has a standard error of measurement (SEM) of 4.410771. The research has found a significant relationship between interest in entrepreneurship education and academic achievement in entrepreneurship education in the study area with Pearson's correlation of 0.378 with significant value of 0.001 at 0.01 level of significance. The hypothesis "there is no significant relationship between interest in entrepreneurship education and academic achievement in entrepreneurship education in colleges of education in north Eastern Nigeria" was therefore rejected based on the significant value of 0.001 (highly significant at $<0.05)$
\end{abstract}

Keywords: Interest inventory, entrepreneurship education, test construction, test validation

\section{Introduction}

The construction and validation of entrepreneurship education interest inventory is borne out of the need to develop a new instrument that would be valid and reliable for the measurement of interest in entrepreneurship education with special reference to the students of colleges of education in north eastern Nigeria. Interest in this regard refers to propensity to be fond of a particular subject and participate more actively in it. Interest is reflected by active participation on part of the students and such interest lead the students to be reading their assignments, or read for pleasure or enjoyment and also seek out for certain activities. It is a situation of desire to be acquainted with or find out about something or somebody. It is that feature that arouses concern or inquisitiveness that holds one's attention. An understanding of student's entrepreneurship interest may be an important component in addressing entrepreneurship concern. To be able to arouse student's interest and persuade them in any subject matter it is essential that the teacher should find out the extent of interest the student(s) have in that subject. This would determine the amount of effort the teacher would put in proper encouragement of the students. With the knowledge of the degree of student's interest in entrepreneurship education, the teachers would find out when and the area in which his students are losing interest in entrepreneurship education and he would try to awaken the student's interest through various acceptable ways. Moreover, it is interesting to note that interest measures tell nothing directly about abilities, though studies have shown that there are certain relationships between abilities and interests (Sidhu, 2012). It is therefore essential to note that, 
interest measures and ability measures deal with two distinct aspects of fitness for a field of study or work. Each provides information that supplements each other.

The National Policy on Education (2014) is the statutory document that put in a nutshell the vision and mission of Nigeria's expectations as they relate to various spheres of education in the country. Therefore, every level of the educational sector draws its policy guidelines and curriculum content from the provision of the National Policy on Education (NPE). One of the goals enshrined in this statute book is that the child should be educated; such that he would acquire the competencies that are necessary for self-reliance and self-sustenance. It is in realisation of this lofty ideals and values that the National Council on Education directed the tertiary education institution agencies to prepare training programmes for take-off of full scale entrepreneurship education activities. It is in compliance with this directive that the entrepreneurship education is inserted into the National Commission for Colleges of Education (NCCE, 2012), Minimum Standards with special emphasis on Entrepreneurship in Agricultural Education, Business Education, Fine and Applied Arts, Home Economics and Technical Education.

However, it is an indisputable fact that, if students/learners have no interest in entrepreneurship education, it is obvious that this initiative would be an exercise in futility. This is because in everyday thinking as well as in educational and psychological discussions of learning and development, the concept of interest plays an important role.It is based on this background that the researcher developed interest inventory to measure the student's interest in entrepreneurship education particularly among the students of vocational education of colleges of education in North Eastern Nigeria.

\section{Statement of the Problem}

This research is primarily concern with constructing and validating a new instrument (EEII). This is due to the fact that, there is no entrepreneurship education interest inventory available for the measurement of interest especially in college of education in North Eastern Nigeria.

\section{Objectives of the Study}

The general objective of the study is to Develop and Validate Entrepreneurship Education Interest Inventory

(EEII) with the following specific objectives:

- To determine the construct validity of the Entrepreneurship Education Interest Inventory (EEII)

- To determine the reliability (internal consistency) of the Entrepreneurship Education Interest Inventory (EEII)

- To find out the Standard Error of Measurement of the Entrepreneurship Education Interest Inventory (EEII)

- To find out whether there is relationship between interest in entrepreneurship education and academic achievement in entrepreneurship education among students of vocational education in colleges of education in North Eastern Nigeria.

\section{Research Questions}

- To what extent does the Entrepreneurship Education Interest Inventory (EEII) possess construct validity?

- To what extent does the Entrepreneurship Education Interest Inventory (EEII) possess reliability (internal consistency)?

- What is the Standard Error of Measurement for the entrepreneurship Education Interest Inventory (EEII)?

\section{Research Hypothesis}

There is no significant relationship between students' interest in entrepreneurship education and academic achievement in entrepreneurship education in colleges of Education in North Eastern Nigeria.

\section{Literature Review}

\subsection{Concept of Test Development}

Test development is a quality-driven process for creating an objective and a standardised test for better evaluation (Umar, 2018). The development of valid, reliable and usable test involves proper planning. The planning entails designing a framework that can guide the test developer in item development process (Okonkwo, 2006). This is necessary because validity, reliability and usability of a test depend on how cautious the test is planned and developed. In line with the foregone argument, a model of test construction is worth inclusion 'the standards model of test construction' which was developed by a joint committee of fifteen leading testing experts and Professionals appointed by the American Psychological Association, the American Educational Research Association, and the National Council on Measurement in Education (National Research Council of USA, 2004). The model suggested the following sequential and logical steps; specify the purpose of the test and inferences to be drawn, develop frameworks describing the knowledge and skills to be tested, build test specification, create potential test items and scoring rubrics, review and pilot test items, and evaluate the quality of items. These steps are considered the most widely accepted guidelines (National Research Council of USA, 2004).

\subsection{Test Validation}

Validation is the process of giving something a strong and firm base, and a value that canbe defended and used in certain conditions. It is also making something acceptable because it is logical and made with correct formalities (Nworgu, in Moneth 2012).Validity is the extent to which an instrument measures what it is intended or purports to measure which is determined by correlation between its results and some other criterion of what it was devised to measure. It is agreed 
among educationists and measurement experts that one of the most important single considerations in test evaluation is the degree of validity of the test. Obe, in Moneth (2012), explained that the validity ofa measuring instrument is its truthfulness or the extent to which the instrument measures what it purports to measure. In a similar statement Onyike, in Moneth (2012), explained validity to mean the capacity of an evaluation device to provide evidence of measuring what it is intended to measure. The author continued by saying that validity refers to the appropriateness of learning experiences presented in school. According to the author, if a question is asked about learning experience, whether it has resulted to a change in behaviour with respect to the objective, and the answer is a positive one, then the experience is said to be valid.

\subsection{Interest Inventory}

Interest inventory is an objective and a standardised self-report instrument used in the measurement of people's interests in vocation, academic field or any other desirable activity. Anikweze (2012) described interest inventory as a way of assessing individual's 'like' and 'dislike' for a number of activities, objects and vocations. The assessment is based on the self-estimate of the learner's rating of their intrinsic interest as different from expressed or manifested interest. According to Anastasi and Urbina (2012), the large majority of interest inventories are designed to assess the individual's interest in different fields of work. Some also provide an analysis of interest in educational curricula or field of study, which in turn are usually related to career decisions. Generally there are two types of interest inventories. These are vocational interest inventory and non-vocational interest inventories (Sidhu, 2012). Vocational interest inventories are designed purposely to assess the interest of students or applicants in relation to a particular job or certain group of jobs. While non-vocational interest inventories are designed to assess the student's interest in relation to a particular field of study or other related matters. Some of the examples of popular interest inventories are Strong interest inventory prepared by E.K Strong which is suitable for senior high school pupils and college groups and Kuder Occupational Interest Survey which is suitable for ninth grade and above.

\section{Theoretical Framework}

In this research Hidi and Renninger's (2006) four-phase model of interest development was discussed to serve as theoretical foundation that informed and guided the development of the inventory.Hidi and Renninger (2006) conceptualised the development of interest into a four phase model. Each phase of interest is distinguished from the other phase based on affect, knowledge, and value. Also, the categories are based on one's own experience, temperament, and genetic predisposition toward an activity and can deviate depending on the person's effort, self-efficacy, and goal setting. The first phase is triggered situational interest and is characteristic of how an activity can attract a person's attention. It starts from an external factor, such as an exposure to a topic in areas that include activities such as group work and puzzles. The second phase is maintained situational interest, which is characterised by increased concentration on a topic. The reason attention is sustained in this phase is the person may develop feelings of value and importance towards that topic.The third phase is emerging individual interest, which is marked by accumulated knowledge and the use of some meta-cognitive skills. Once in this phase, the topic is usually one that brings forth affirming emotions and value.The fourth phase is a well-developed individual interest, which is characterized by perseverance in the face of adversity. This type of interest can bring about the same affirming emotions that the previous phase brought; however, individuals are more likely to engage themselves in the topic. Hidi and Renninger's (2006) four-phase model of interest outlined the specific development of interest in different levels. This criterion is important when measuring interest because it allows one to acquire specific information. The different phases of interest are characterised by the information that comprises them, and each phase of interest encompasses positive emotions, value, knowledge, and meta-cognitive components. Therefore, each phase has certain characteristics that are easily categorized to determine which phase an individual may be experiencing.

\section{Methodology}

The study used instrumentation as its research design. The population of the study consists of all NCE II students in schools of vocational and technical education of Umar Suleiman College of Education Gashua, Federal College of Education Technical Gombe, Aminu Saleh College of Education Azare, Kashim Ibrahim College of Education Maiduguri, College of Education Zinc and College of Education Hong, in Yobe, Gombe, Bauchi, Borno, Taraba, and Adamawa States respectively, which were exactly 2898 students. Samples of nine hundred and fifty two (952) students were randomly selected for the study from the six colleges of education using stratified random sampling. Hidi and Renninger's (2006) four-phase model of interest development was used to serve as theoretical basis that informed and guided the process of development and validation of the interest inventory.

\section{Result and Discussion}

\subsection{Research Question one}

To what extent does the Entrepreneurship Education Interest Inventory (EEII) possess construct validity?

Table 1.1, 1.2 and 1.3 and 1.4 showed evidence of convergence construct validity of the instrument. 


\begin{tabular}{|c|c|c|c|c|c|c|}
\hline \multirow[t]{2}{*}{ Items } & \multicolumn{2}{|c|}{ Communalities } & \multicolumn{4}{|c|}{ Factor Loading } \\
\hline & Initial & Extraction & Factor 1 & Factor 2 & Factor 3 & Factor 4 \\
\hline V 1 & 1.000 & .707 & .709 & & & \\
\hline $\mathrm{V} 2$ & 1.000 & .715 & .803 & & & \\
\hline V3 & 1.000 & .624 & .759 & & & \\
\hline V 4 & 1.000 & .680 & .795 & & & \\
\hline V 5 & 1.000 & .618 & .784 & & & \\
\hline V6 & 1.000 & .785 & & .861 & & \\
\hline V7 & 1.000 & .863 & & .912 & & \\
\hline V8 & 1.000 & .483 & & .665 & & \\
\hline V9 & 1.000 & .521 & & .651 & & \\
\hline V 10 & 1.000 & .739 & & .762 & & \\
\hline V 11 & 1.000 & .795 & & & .850 & \\
\hline V 12 & 1.000 & .721 & & & .800 & \\
\hline V 13 & 1.000 & .718 & & & .740 & \\
\hline V 14 & 1.000 & .759 & & & .820 & \\
\hline V 15 & 1.000 & .724 & & & .794 & \\
\hline V 16 & 1.000 & .832 & & & & .833 \\
\hline V 17 & 1.000 & .767 & & & & .825 \\
\hline V 18 & 1.000 & .833 & & & & .808 \\
\hline V 19 & 1.000 & .653 & & & & .798 \\
\hline V 20 & 1.000 & .700 & & & & .710 \\
\hline KMO & .772 & & & & & \\
\hline $\mathrm{X}^{2}$ & 4313.204 & & & & & \\
\hline Df & 190 & & & & & \\
\hline P-value & & & & & & \\
\hline
\end{tabular}

Table 1: Factor Analysis, KMO of Sampling Adequacy and Bartlett's Test of Sphericity

The above table contained communality table and rotated component matrix. The table shows the variance before and after extraction. Principal components analysis assumes that before the extraction all the variance is common and is 1. After the extraction; with levelled column as Extraction is the shared or common variance in the data set. For instance for factor 1 , its $71 \%$ variance is a shared variance in the data set. While on the other hand, the table also contains the rotated components matrix which shows how each variable is loaded onto each factor. SPSS has been asked to suppressed any loading of value $<0.5$, and hence all the factors loading displayed are greater than 0.5 . The table also shows thatitems 1,2 , 3,4 , and 5 have all loaded on factor 1 (all from the same variable; knowledge), items 6, 7, 8, 9, and 10 have also loaded on factor 2 (all from the same variable; Positive emotion), items 11, 12, 13, 14, and 15 (all from the same variable; Value), have loaded on factor 3 , and lastly, items 16, 17, 18, 19 and 20 have loaded on factor 4 (all from the same variable; Engagement). The table has revealed a very nice result because each of the 4 factors loaded on 5 related inventory items; this loading of the variable among the factors revealed evidence of construct validity of the instrument. The other part of the table revealed that, the KMO value of 0.772 shows that the pattern of the correlations are relatively compact and so factor analysis from the data yielded distinct and reliable factors; KMO value of greater than 0.5 is the acceptable value. Bartlett's Test of Sphericity tests the null hypothesis that correlations matrix is an identity matrix. From the test (Chisquare of 4313.204), the null hypothesis was rejected based on the significant value of 0.001 (highly significant at <0.05) and the conclusion is that the correlation matrix is not an identity matrix and that there is relationships among the variables used in the analysis.

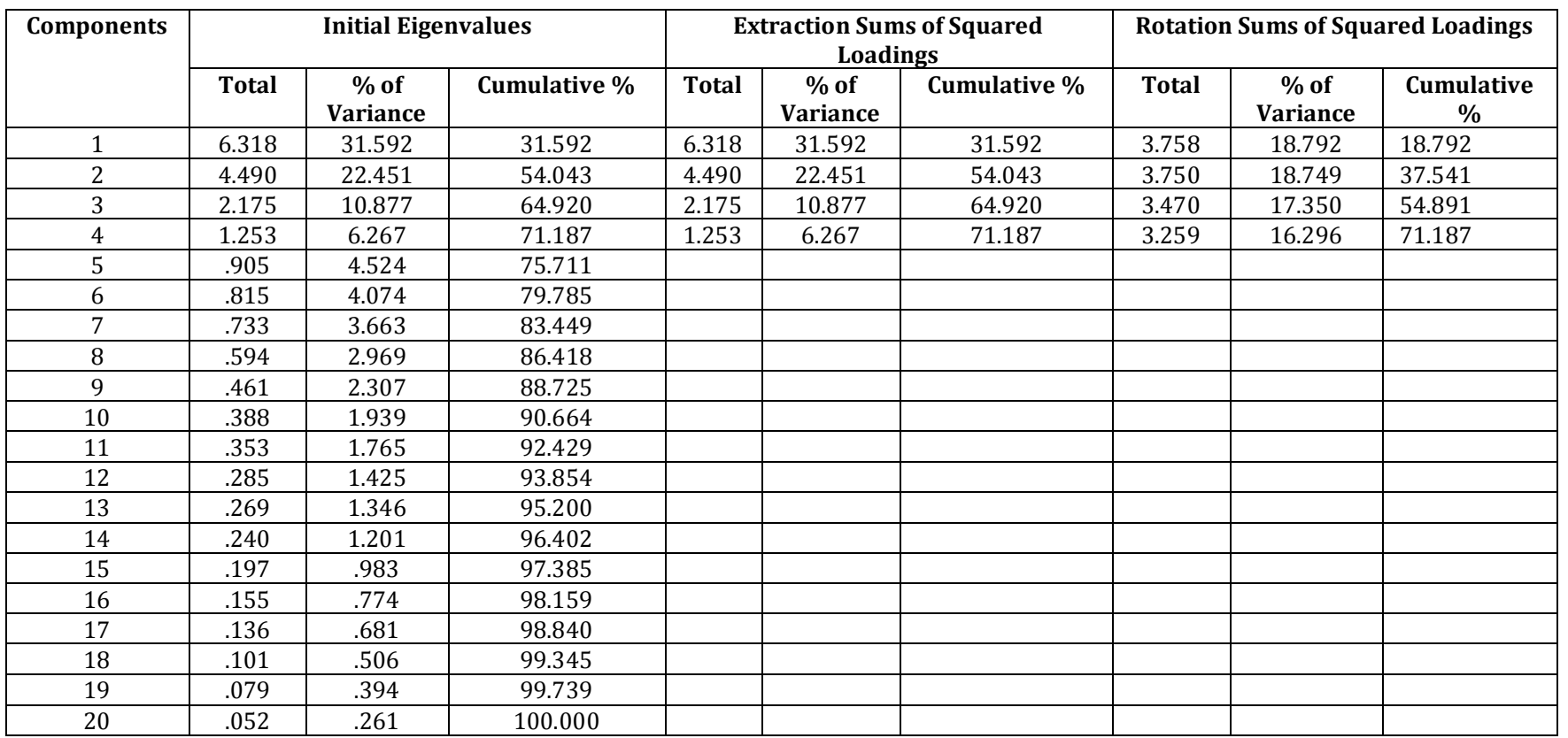

Table 2: Principal Component Analysis (Variance Explained) 
The table above shows the eigenvalues associated with each factor; before extraction, after extraction and after rotation. SPSS package has identified 20 factors (equals the number of items in the inventory) from the data set. The eigenvalue of each factor represents the variance explained by that factor and its respective percentage is displayed. For instance, before the extraction, factor 1 explains $31.59 \%$ of the variance, factor 2 explains $22.45 \%$ of the variance, factor 3 explains $10.88 \%$ of the variance, factor 4 explains $6.27 \%$ of the variance and so on. Factors $1,2,3$ and 4 account for $71.19 \%$ of the variance and they all have respective eigenvalues of $>1$. After the extraction all the figures are the same as before the extraction unless for the fact that any factor with an eigenvalue of $<1$ is not retained and hence the package retains only four factors from the data sets. After the rotation, the eigenvalues of the factors retained displayed and are not much dispersed and their respective variance percentage is also close to one another in order to equalize the relative importance of each factor. The major take away from the above table is that 4 factors has been extracted which were retained for further analysis and they all together contributed for $71.19 \%$ of the variance.

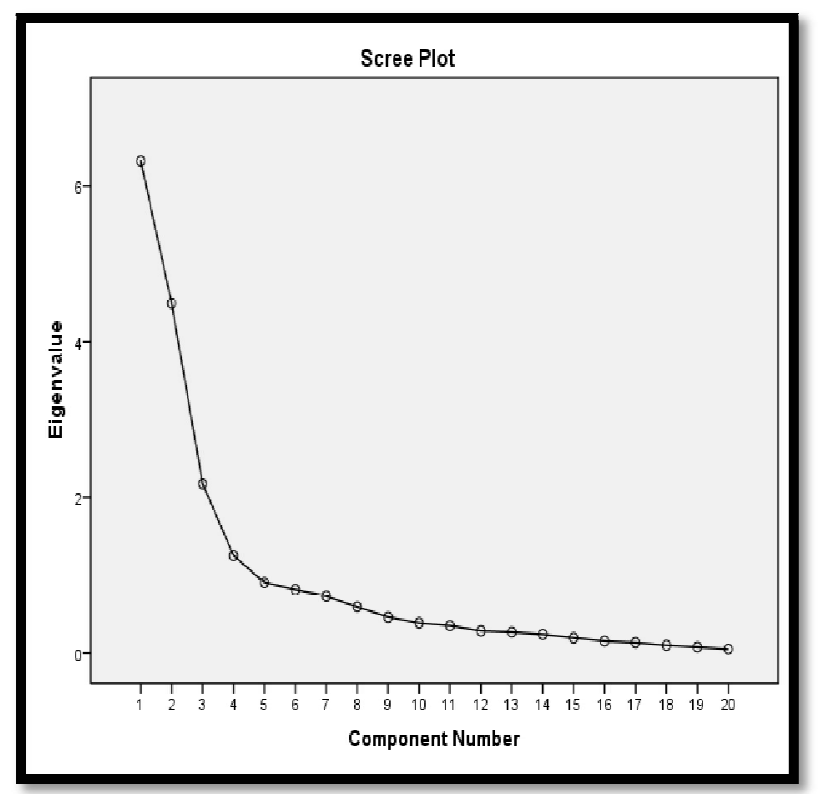

Figure 1: Scree Plot Further Explains Table 2Above

The Scree Plot above shows that in the data set possibly 4 factors will be retained for further analysis. This is established from the point where the plot starts to become flat at tail and also at a point where the eigenvalue is greater than 1 , in this case after point 4 the plot becomes flat at the tail.

\begin{tabular}{|c|c|c|c|c|c|c|c|c|c|c|c|}
\hline \multicolumn{3}{|c|}{ Knowledge } & \multicolumn{3}{c|}{ Positive Emotion } & \multicolumn{3}{c|}{ Value } & \multicolumn{3}{c|}{ Engagement } \\
\hline $\mathrm{B}$ & $\beta 2$ & 3 & $\beta$ & $\beta 2$ & 3 & $\mathrm{~B}$ & $\beta 2$ & 3 & $\mathrm{~B}$ & $\beta 2$ & 3 \\
\hline 0.85 & 0.7225 & 0.1275 & 0.912 & 0.831744 & 0.080256 & 0.803 & 0.644809 & 0.158191 & 0.833 & 0.693889 & 0.139111 \\
\hline 0.82 & 0.6724 & 0.1476 & 0.861 & 0.741321 & 0.119679 & 0.795 & 0.632025 & 0.162975 & 0.825 & 0.680625 & 0.144375 \\
\hline 0.8 & 0.64 & 0.16 & 0.762 & 0.580644 & 0.181356 & 0.784 & 0.614656 & 0.169344 & 0.808 & 0.652864 & 0.155136 \\
\hline 0.794 & 0.630436 & 0.163564 & 0.665 & 0.442225 & 0.222775 & 0.759 & 0.576081 & 0.182919 & 0.798 & 0.636804 & 0.161196 \\
\hline 0.74 & 0.5476 & 0.1924 & 0.651 & 0.423801 & 0.227199 & 0.709 & 0.502681 & 0.206319 & 0.71 & 0.5041 & 0.2059 \\
\hline 4.004 & 3.212936 & 0.791064 & 3.851 & 3.019735 & 0.831265 & 3.85 & 2.970252 & 0.879748 & 3.974 & 3.168282 & 0.805718 \\
\hline \multicolumn{3}{|c|}{ AVE = 0.7702 } & \multicolumn{3}{c|}{ AVE $=0.77$} & & \multicolumn{3}{c|}{ AVE $=0.7948$} \\
\hline
\end{tabular}

Table 3: Average Variance Extracted

The above table showed the convergence of the variance to the four factors; knowledge with average variance extracted of 0.8008 , positive emotion with average variance extracted of 0.7702 , value with average variance extracted of 0.77 and engagement with average variance extracted of 0.7948. According to Alarcon and Sanchez (2015), convergent validity of a measurement model can be assessed by the Average Variance Extracted (AVE). They further stated that, values above 0.7 are considered very well, whereas, the level of 0.5 is acceptable. Therefore, going by the above average variance extracted values of $0.8008,0.7702,0.77$ and 0.7948 for knowledge, emotion, value and engagement respectively, the researcher concludes that, the instrument showed evidence of convergent construct validity.

\subsection{Research Question Two}

To what extent does the Entrepreneurship Education Interest Inventory (EEII) possess reliability (internal consistency)? 


\begin{tabular}{|c|c|}
\hline Cronbach's Alpha & Number of Items \\
\hline .878 & 20 \\
\hline
\end{tabular}

Table 4: Shows the Reliability of the Entrepreneurship Education Interest Inventory (EEII)

The above table showed the reliability (internal consistency) for all the twenty items of the Entrepreneurship Education Interest Inventory (EEII) with Cronbach's Alpha value of .878. This value revealed the internal consistency of the instrument. According to Buba (2012), this method provides reliability results for instrument composed of items that are having varying point values or attitude scale that provides responses, such strongly agree, agree, disagree and strongly disagree.

\subsection{Research Question Three}

What is the Standard Error of Measurement (SEM) of the Entrepreneurship Education Interest Inventory (EEII)? The Standard Error of Measurement of the Entrepreneurship Education Interest Inventory (EEII) is shown below:

$$
S E M=S D \sqrt{1}-r
$$

Standard Error of Measurement is estimated by multiplying the standard deviation of the sample scores by the square root of 1 minus reliability of scores.

$=4.410771$

$$
S E M=12.628 \sqrt{1}-.878
$$

The developed Entrepreneurship Education Interest Inventory (EEII) has a standard error of measurement (SEM) of 4.410771. SEM allows us to quantify the extent to which a test provides accurate scores. So low level of standard error of measurement indicate high level of score accuracy and conversely high level of standard error of measurement indicate low level of score accuracy. The SEM value of 4.410771 (which is low) indicated high level of scorer accuracy.

\subsection{Null Hypothesis}

There is no significant relationship between student's interest in entrepreneurship education and academic achievement in entrepreneurship education in Colleges of Education in North Eastern Nigeria.

\begin{tabular}{|c|c|c|c|}
\hline \multicolumn{2}{|c|}{} & EEII & EEAT \\
\hline EEII & Pearson Correlation & 1 & .378 \\
\hline & Sig. (2-tailed) & & .000 \\
\hline & $\mathrm{N}$ & 952 & 952 \\
\hline EEAT & Pearson Correlation & .378 & 1 \\
\hline & Sig. (2tailed) & .000 & 952 \\
\hline
\end{tabular}

Table 5: Pearson's Correlation

This table shows the Pearson's correlation of .378 with significant value of 0.001 for the Entrepreneurship Education Interest Inventory (EEII) and Entrepreneurship Education Achievement Test (EEAT) of the 952 sample in all the study area. The Correlation is significant at the 0.01 level of significance. Therefore, the null hypothesis was rejected based on the significant value of 0.001 (highly significant at $<0.05$ ).

\section{Conclusion}

For the purposes of this study, the following conclusions were drawn: The developed entrepreneurship education interest inventory is valid for measuring interest in entrepreneurship education. This is because the instrument has shown evidence of convergent construct validity. The developed entrepreneurship education interest inventory is also reliable for measuring interest and has shown Cronbach's Alpha Coefficient of 0.878. The instrument indicates high level of score accuracy with Standard Error of Measurement (SEM) of 4.410771. The study also established evidence of relationship between interest in entrepreneurship education and academic achievement in entrepreneurship education among the students of the six colleges of education with Pearson's correlation of 0.378 with significant value of 0.001 respectively at 0.01 level of significance.

\section{Recommendation}

From the findings of the study, the following recommendations are made:

- The instrument has shown evidence of convergent validity, using Confirmatory factor analysis (CFA) and Average Variance Extracted (AVE). Therefore, the EEII can be used for assessing student's interest in entrepreneurship education in colleges of education.

- Even though, the instrument is reliable with Cronbach Alpha coefficient of 0.878 , the instrument should also be re-tested with larger sample to confirm the reliability of the instrument.

- Since the study revealed the significant relationship between interest and academic achievement, teachers should give student's interest priority just as they gave to academic achievement. 


\section{References}

i. Anastasi, A. \& Urbina, S. (2012). Psychological Testing $7^{\text {th }}$ Edition. New Delhi: PHI Learning Private Ltd.

ii. Anikweze, C.M. (2012). Measurement and Evaluation for Teacher Education. Enugu: SNAAP Press Ltd. Nigeria.

iii. Buba, A.A. (2012). Tools for Educational Measurement and Probability. Ibadan: BOGA PRESS.

iv. Hidi, S., \& Renninger, K. (2006).The four-phase model of interest development. Educational Psychologist, 41(2), 111-127.

v. Moneth, C.U. (2012), Development and Validation of Economics Achievement for Senior Secondary School Students. Unpublished M. Ed Thesis, University of Nigeria Nsuka

vi. National Commission for Colleges of Education, (2012). NCCE Minimum Standards. Garki Abuja Federal Government of Nigeria.

vii. National Policy on Education, (2014). NERDC Press, Yaba Lagos. Federal Government of Nigeria.

viii. National Research Council, (2004).The Test Development Process: Redesigning the US Naturalization Tests: Interim Report. Washington DC The National Academies Press. USA.

ix. Okonkwo, C.A. (2006). Measurement and Evaluation. Lagos: Regent (printing and Publishing) Ltd. Nigeria.

x. Sidhu, K.S. (2012).New Approaches to Measurement and Evaluation. New Delhi: Sterling Publishers Ltd. India.

xi. Umar, S.M (2018). Development and Validation of Entrepreneurship Education Interest Inventory in College of Education in Yobe State. Unpublished M. Ed Dissertation, Bayero University, Kano Nigeria 